\title{
A PROGRAMAÇÃO E O CONTROLE DA PRODUÇÃO EM AMBIENTE DE INCERTEZA E ATIVOS CAROS: O CASO DE UMA EMPRESA TERMOPLÁSTICA DO PÓLO INDUSTRIAL DE MANAUS
}

\section{THE PRODUCTION PROGRAMMING AND CONTROL IN AN UNCERTAIN ENVIRONMENT WITH EXPENSIVE ASSETS: THE CASE OF A THERMOPLASTIC INDUSTRY IN THE MANAUS INDUSTRIAL POLE}

\author{
Maria Rosália da Silva Mizoguchi ${ }^{1}$; Eduardo Galvão Moura Jardim²; Ricardo Sarmento Costa ${ }^{3}$ \\ ${ }^{1}$ Universidade Federal do Amazonas - UFAM - Manaus - Brasil \\ rmizoguchi@me.com \\ ${ }^{2}$ Universidade Federal do Rio de Janeiro - UFRJ - Rio de Janeiro - Brasil \\ eduardo@tgps.com.br \\ ${ }^{3}$ Trilha da Inovação - Projetos Tecnológicos e Educacionais - Rio de Janeiro - Brasil \\ ricardo@trilhaprojetos.com.br
}

\begin{abstract}
Resumo
Em um segmento industrial com altos investimentos em ativos - como máquinas e moldes - cujas capacidades de processamentos são limitadas e planos de vendas variam continuamente na tentativa de se adequar a diferentes necessidades de variados clientes, a programação e o controle diário de produção tornam-se naturalmente complexos, e tem um papel decisivo no desempenho do negócio. Este é o caso de uma empresa do setor termoplástico do Pólo Industrial de Manaus (PIM) que para operar nesse quadro de variedade e variabilidade de demandas, produtos, insumos e processos, desenvolveu e implantou um sistema integrado de gestão da capacidade de produção. Dentre os seus módulos, este sistema possui um simulador para a programação com capacidade finita, que considera características particulares dos processos de produção e de gestão, que serão descritos neste artigo. Os resultados obtidos com o uso do sistema incluem: redução de $75 \%$ na quantidade de peças produzidas indevidamente por erro de planejamento; redução de $70 \%$ no tempo de resposta de análise dos pedidos dos clientes; redução de 2:33h no tempo de planejamento de um programa de produção, que antes era de 3:00h. Alguns resultados inesperados foram alcançados, como o ganho de $1.000 \mathrm{~m}^{2}$ de área no almoxarifado de peças. Com este trabalho foi possível que pessoas portadoras de $100 \%$ de deficiência visual pudessem fazer o monitoramento da produção, onde se conseguiu com o uso deste módulo, dentre outros, a redução de 0,7\% de paradas de máquinas.
\end{abstract}

Palavras-chave: planejamento programação e controle da produção; simulação computacional; programação com capacidade finita.

\section{Formulação do problema}

Há duas décadas em atuação na área de planejamento, programação e controle da produção, em empresas instaladas no PIM, foi possível para os autores analisar em detalhes aspectos 
conceituais e práticos do seqüenciamento e acionamento da produção do dia-a-dia de uma fábrica. Uma constatação é que a maioria das empresas que fazem uso de sistemas corporativos (próprios ou não); não oferecem uma solução para apoiar a programação, o seqüenciamento e o acionamento diário da produção.

Isto é particularmente verdade em ambientes com alta variedade de produtos, insumos e processos. Nesse contexto, não raro encontram-se efetivamente em uso planilhas eletrônicas customizadas para a busca de soluções de problemas de PPCP - planejamento, programação e controle de produção para setores específicos do sistema de manufatura. Não obstante a sua real e reconhecida utilidade, estas planilhas estão por vezes desconectadas dos sistemas corporativos. Valem-se de uma base de dados própria, contemplando questões locais do processo de produção, porém nem sempre alinhadas aos objetivos estratégicos da empresa.

Em outras palavras, verifica-se que na realidade de muitas empresas existe uma lacuna considerável entre as decisões estratégicas assumidas nos níveis mais altos das corporações e as decisões tomadas no dia-a-dia do chão-de-fábrica. "Gerir as atividades do curto prazo estrategicamente significa programar e acionar a produção tendo em vista também os impactos destas decisões do dia-a-dia no longo prazo do negócio" (JARDIM; COSTA, 2003).

Para atingir tal objetivo, vale ainda notar que qualquer mudança e/ou introdução de uma nova tecnologia em um ambiente industrial, como uma ferramenta computacional de planejamento, programação e controle da produção pode ser acompanhada de percalços para a utilização inicial e plena das suas soluções. Percalços estes decorrentes da dificuldade de se integrar a tecnologia de gestão a pessoas e procedimentos já existentes na organização.

Todas essas questões foram encontradas na empresa objeto deste estudo, a qual opera no ramo da indústria de transformação termoplástica, com a produção que inclui dois tipos de processo: de injeção plástica e de acabamento.

- No processo de Injeção Plástica tem-se: 72 máquinas injetoras com capacidade que variam de 80 ton a 1.600 ton. Com uma capacidade de transformação de 1.650 ton/mês. As máquinas deste parque fabril são consideradas as de mais alta tecnologia disponível no mercado, oriundas da Europa, onde o valor médio de uma unidade é de US\$ 550 mil.

- No processo de Acabamento, tem-se: 13 linhas de Pintura, com disponibilidade de 56 Tampo print e 6 Hot stamping. Com capacidade média em cada Linha de 487.500 peças/mês.

Como pode ser visto, trata-se de um parque com investimentos em instalações fabris na ordem de US\$ 47 milhões.

Por fim, vale ressaltar que durante o período de desenvolvimento desse trabalho, a demanda superava a capacidade de produção da empresa. 


\section{Objetivo}

Diante do contexto descrito, este artigo tem como objetivo apresentar e avaliar a utilidade de um sistema integrado de gestão da capacidade de produção, desenvolvido e estudado no âmbito da empresa de referência, que permitisse melhorar o desempenho particularmente das seguintes características do negócio:

a) Pontualidade: cumprimento de prazos de entrega dos produtos acordados com os clientes;

b) Qualidade: entrega dos produtos solicitados conforme especificações dos clientes;

c) Custos: redução dos custos de produção pela melhor utilização de recursos, com a diminuição de subcontratações, horas-extras e estoques;

d) Velocidade (Utilização dos ativos): redução de paradas de máquinas e linhas de acabamento;

e) Flexibilidade: facilidade e rapidez para atender mudanças no mix de produção, na variação da quantidade solicitada e na alteração das datas de entrega; além disso, possibilitar a rápida introdução de novos produtos e, proporcionar agilidade no uso de alternativas frente às quebras de máquinas e falta de materiais e colaboradores.

$\mathrm{Na}$ busca desses objetivos, aproveitou-se a oportunidade para também tornar um sistema PPCP operável por pessoas portadoras de deficiência visual em 100\% e contribuir com a inserção das mesmas no mercado de trabalho.

\section{Referencial teórico e ferramental}

O Quadro 1 procura capturar a essência do planejamento, programação e controle da capacidade de produção, no âmbito de três clássicas abordagens de gestão de manufatura.

Quadro 1 - Planejamento, Programação e Controle da Capacidade de Produçãono âmbito das Abordagens Clássicas de

Gestão de Manufatura - uma síntese

\begin{tabular}{|c|c|c|c|}
\hline Denominação / Siglas & $\begin{array}{c}\text { Foco / ponto } \\
\text { de partida }\end{array}$ & $\begin{array}{c}\text { Objetivo central - } \\
\text { ESTABELECER o: }\end{array}$ & $\begin{array}{c}\text { Paradigmas da visão de CAPACIDADE } \\
\text { como critério inicial de análise / } \\
\text { consideração e provisão }\end{array}$ \\
$\begin{array}{c}\text { MRP } \rightarrow \\
\text { MRPII } \rightarrow \text { ERP } \rightarrow\end{array}$ & $\begin{array}{c}\text { Gestão de } \\
\text { Materiais }\end{array}$ & $\begin{array}{c}\text { Quando e Quanto } \\
\text { comprar ou produzir } \\
\text { (de forma integrada e } \\
\text { eficiente) }\end{array}$ & $\begin{array}{c}\text { Ainda que avaliada inicialmente a luz de um } \\
\text { potencial recurso crítico, a capacidade (no } \\
\text { cálculo do quando e quanto) é considerada } \\
\text { ilimitada (infinita) para outros recursos de } \\
\text { produção, devendo ser posteriormente } \\
\text { ajustada, se necessário e possível. }\end{array}$ \\
\hline JIT $\rightarrow$ LEAN & $\begin{array}{c}\text { Gestão de } \\
\text { Fluxo }\end{array}$ & $\begin{array}{c}\text { Fluxo Contínuo de } \\
\text { valor para o cliente } \\
\text { (removendo os } \\
\text { desperdícios) }\end{array}$ & $\begin{array}{c}\text { Em princípio, a capacidade é considerada } \\
\text { ajustável a demanda takt-time) }\end{array}$ \\
\hline
\end{tabular}




\begin{tabular}{|c|c|c|c|}
\hline OPT/DBR $\rightarrow$ ToC & $\begin{array}{c}\text { Gestão de } \\
\text { Capacidade }\end{array}$ & $\begin{array}{c}\text { uso (de forma eficaz) } \\
\text { da restrição/gargalo } \\
\text { de produção (para o } \\
\text { alcance da meta de } \\
\text { venda e fazer \$) }\end{array}$ & $\begin{array}{c}\text { A capacidade é considerada finita e } \\
\text { determinada (limitada) por uma restrição ou }\end{array}$ \\
gargalo definido (recurso restritivo de \\
\hline
\end{tabular}

Fonte: Autoria própria (2008)

Ainda que diferentes conceitos e ferramentas dessas abordagens clássicas possam ser aplicáveis e estejam em uso no contexto em referência, a programação de capacidade propriamente dita não pode ficar restrita - de per si - a cada um desses paradigmas gerenciais. Isto porque:

a) O que determina a aceitação de um pedido não é apenas (ou primeiramente) a questão de materiais (como no caso do MRP), mas principalmente a disponibilidade real de capacidade de diferentes recursos (e não apenas de um potencial recurso crítico, como no caso do MRP II) que precisam ser considerados logo no início para diferentes mix de produção;

b) Como o sistema de produção envolve ativos caros e limitados (máquinas injetoras e linhas de acabamento), com ciclos de processos definidos e inflexíveis, a sua capacidade não pode ser contínua e facilmente ajustada ao ritmo da demanda (como no caso do paradigma JIT/LEAN);

c) Ainda que a abordagem OPT/DBR - ToC tenha a capacidade como o ponto focal da programação da produção, clientes sem aviso prévio mudam constantemente o mix de produtos demandado, fazendo com o gargalo ou a restrição seja dinâmico - isto é, não estável e frequentemente imprevisível. Este fato é ainda agravado quando surgem indesejáveis, mas reais problemas de produção como quebras de máquinas, falta de materiais e pessoas.

Diante de todo esse quadro, optou-se por aplicar uma abordagem que possibilitasse capturar a qualquer momento essa variedade e variabilidade de demandas e processos e que permitisse que reprogramações da produção fossem rapidamente feitas para cada situação encontrada - motivo pelo qual se optou por sistemas com simulação valendo-se da programação com capacidade finita ou Finite Capacity Scheduling (FCS).

Esta abordagem se enquadra no âmbito da Figura 1 da arquitetura Manufacturing Execution System (MES), onde a Manufacturing Execution System Association - MESA International (2004) apud Corrêa et al (2008, p. 323) define que "um sistema de execução e controle da fábrica ou simplesmente MES é um sistema de chão-de-fábrica orientado para a melhoria de desempenho que complementa e aperfeiçoa os sistemas integrados de gestão (planejamento e controle) da produção". Nesse ambiente, é comum quando da implantação de um novo sistema, que todos os dados ou as informações julgadas pertinentes para o processo de simulação na ferramenta, não estejam prontamente disponíveis na organização. 


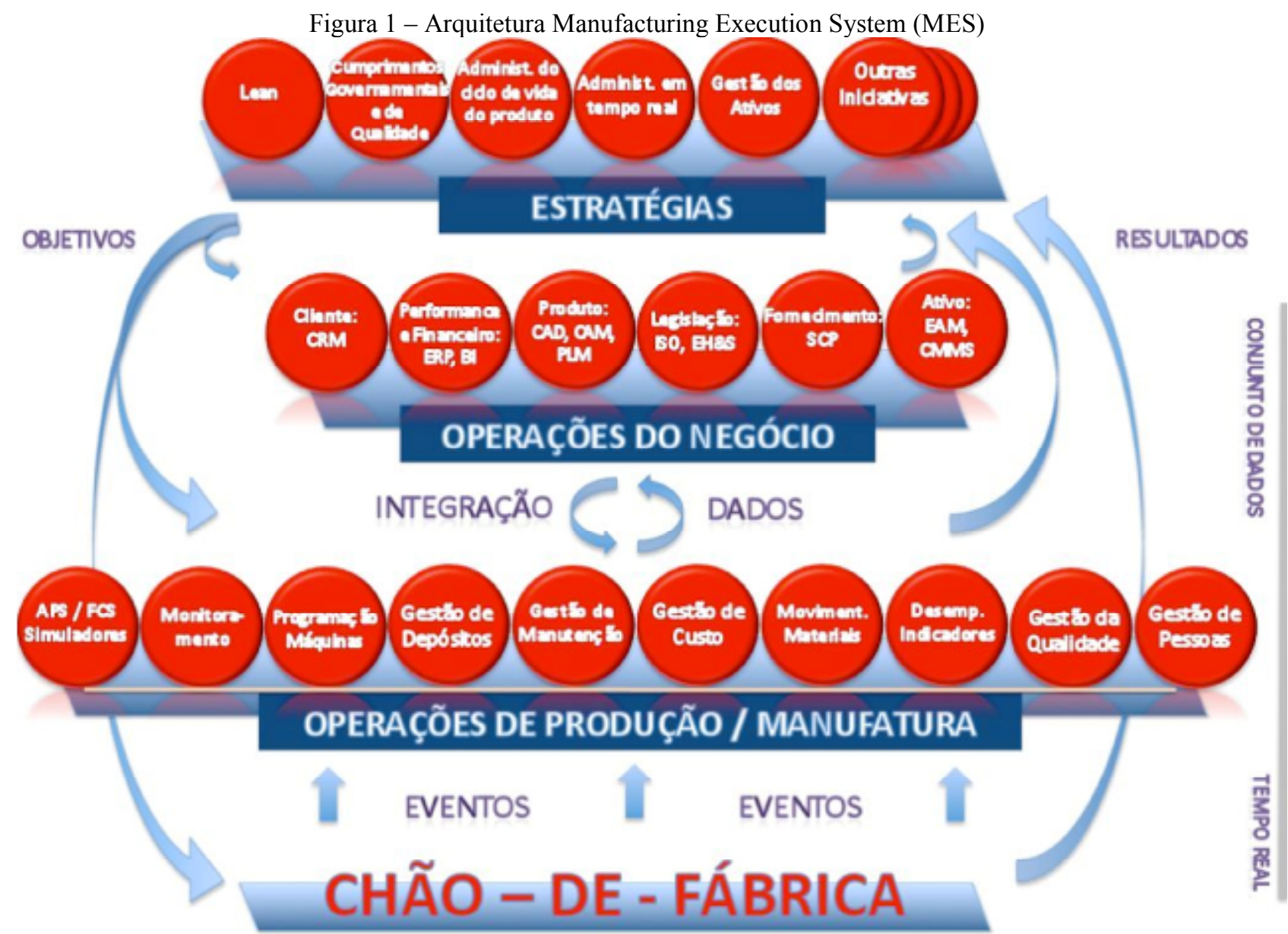

Fonte: Adaptado e expandido de MESA (2010)

Focando-se agora especificamente o processo de planejamento hierárquico da organização, o Simulador atua no nível das operações de produção / manufatura, diretamente no nível do PC3, conforme descrito na Figura 2.

Figura 2 - Gestão da Capacidade - Visão Hierárquica

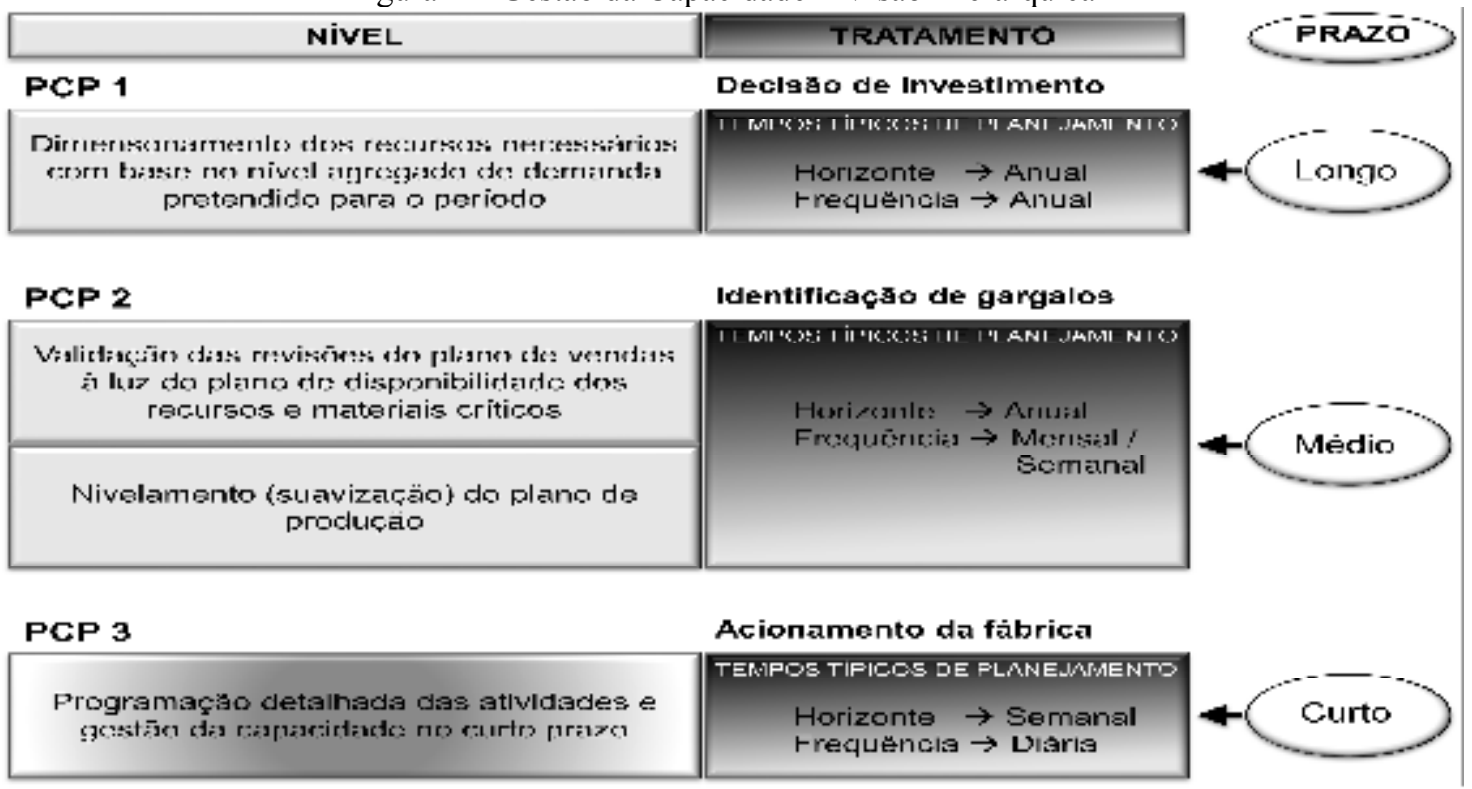

Fonte: Adaptado de Jardim e Costa (1994) 
O PCP1 - o planejamento de longo prazo - é o que determina os investimentos necessários (como a aquisição de máquinas e a ampliação da fábrica) para atender a um nível agregado de demanda, sendo tipicamente revisto com uma freqüência anual.

O PCP2 - o planejamento de médio prazo - é necessário para a validação dos planos de venda e produção mais firmes e precisos, contemplando horizontes de tempo normalmente menores que um ano. Nesse processo, a produção deve ser nivelada através da identificação e eliminação de eventuais e específicos gargalos. Isto é feito, por exemplo, com a aquisição de ativos de mais baixo valor (como embalagens vai-vem); ou com o aumento de uma linha de produção; ou com o incremento de mão-de-obra; ou com a implantação de mais turnos de trabalho; ou com a subcontratação de alguma operação; ou mesmo através da simples melhoria de processos produtivos. A imprevisibilidade da demanda pode fazer com que a freqüência de revisão do PCP2 possa ser mensal, quinzenal e até mesmo semanal.

O PCP3 - o planejamento de curto prazo - é o mais operacional e o que realmente deve refletir o que vai ser feito no dia-a-dia do chão-de-fábrica. Dele resulta o real valor que estará (ou não!) sendo gerado para o cliente e o acionista. Aqui os detalhes terão que ser decisivamente considerados no planejamento. Caso contrário, os objetivos traçados não serão devidamente alcançados. Entre estes detalhes decisivos, destacam-se: (1) os diferentes tempos de setups para mutáveis seqüências de produção; (2) os roteiros de produção alternativos frente a imprevistos; (3) os recursos mais apropriados (em função de sua real eficiência ou qualidade de realização) para determinadas circunstâncias de produtos, tarefas, pessoas e insumos; (4) os variados tamanhos de lotes de processamento e de transferência que podem ser empregados - dentro ou fora dos padrões estabelecidos - para acelerar a produção, atender a um dado cliente (prioritário) ou melhorar o grau de utilização de um recurso crítico.

Entre tantas outras que poderiam ainda ser exemplificadas, estas alternativas gerenciais específicas de cada situação - fazem parte do chamado conhecimento tácito da organização. Trata-se do valioso saber que os colaboradores adquirem com passar do tempo ao executar as suas tarefas e sem o qual a produção não acontece apropriadamente. Mas, se este conhecimento tácito é de um lado fundamental para a obtenção e entrega do produto ao cliente, de outro não costuma estar facilmente disponível nas bases de dados e registros da empresa.

No ambiente MRP/MRP II tradicional, o nível de PCP3 não é contemplado nos cálculos - o que significa dizer que estes sistemas não chegam ao nível de detalhar a ordem (ou prioridade em) que cada tarefa deve ser executada em cada recurso da manufatura.

Já no clássico paradigma LEAN, o propósito é exatamente acabar com esse intricado problema de programação do curto prazo. Isto é resolvido fazendo com que a produção seja sempre puxada a partir das ordens dos clientes. Para tanto, as operações terão que ter seus tempos (de ciclo) 
balanceados de acordo com o ritmo da demanda (takt time) e devem ser alinhadas de acordo com roteiros de produção semelhantes (referentes, por exemplo, a produtos de uma mesma família). E todo o processo deverá funcionar de forma estabilizada e com rotinas padronizadas.

O pressuposto LEAN, portanto, é que haverá capacidade suficiente no sistema para atender a todos os clientes. E o fluxo do produto (lead time) deverá ocorrer de forma rápida e contínua, perseguindo-se constantemente o uso do lote unitário e a retirada de todo e qualquer desperdício (como setups, paradas, filas, reprocessamentos, etc.) que impeçam o alcance desse intento.

Sob a ótica da filosofia de gestão OPT - DBR/ToC, o PCP3 deve focar a sua atenção na programação da restrição do negócio (seja ela uma máquina, uma matéria prima, um molde, entre outras possibilidades). Dessa restrição, deveremos extrair o máximo do seu rendimento. Protegê-la com estoques de segurança para que não pare na eventualidade de falta de insumos. E torná-la o elemento governante do processo, submetendo todos os demais recursos ao seu acionamento. Aqui melhorias contínuas no desempenho da restrição são também buscadas de tal forma que se a mesma for quebrada, com o surgimento de um novo gargalo, todo o processo de (re)planejamento deverá ser refeito.

Conforme descritas em síntese acima, as práticas MRP/MRPII, JIT/LEAN e OPT-DBR/ToC na esfera do PCP3 - quando confrontadas com as necessidades de gerir um sistema com alta variedade e variabilidade de demanda, processos e insumos - reforçam a escolha pela flexível (e não excludente) abordagem da gestão por simulação com capacidade finita.

De fato, no contexto em questão, numa tentativa de se fidelizar clientes, atendendo prontamente as suas demandas em constante mutação, programas de produção são revistos muitas vezes numa freqüência mais do que diária, isto é, turno a turno. Nessas circunstâncias, para se atender a dinâmica carteira de pedidos, são necessárias análises detalhadas das diferentes restrições - presentes e futuras - do processo produtivo onde o tempo tem que ser considerado (e as operações simuladas) minuto a minuto, segundo a segundo.

Para essa tarefa têm-se disponíveis no Brasil diferentes sistemas de programação com capacidade finita. Com base em um estudo a respeito dos mesmos, Pedroso e Corrêa (1997), coloca dentre outras considerações que:

- O grau de maturidade e de sofisticação destes sistemas; variam consideravelmente, bem como os respectivos preços (dentre os sistemas disponíveis comercialmente no Brasil, foram identificados valores que variaram de sete mil a um milhão e meio de dólares). Em geral, os sistemas com soluções proprietárias fechadas são sensivelmente mais caros;

- Nem todos os representantes brasileiros de sistemas fabricados no exterior dominam a tecnologia envolvida no sistema e, notadamente nos casos de sistemas fechados, sabem que o sistema apresenta por dentro. Neste caso, uma eventual necessidade de customização poderia custar ao usuário tempo e recursos financeiros relativamente altos;

- Nem todos os fornecedores e representantes nacionais estão capacitados a dar suporte tanto na análise de adequação da solução a potenciais clientes quanto na própria implantação e apoio técnico ao uso dos aplicativos (PEDROSO; CORRÊA, 1997, p.16). 
Para que tais sistemas possam - efetivamente e rotineiramente - interligar os objetivos estratégicos da corporação com os planos e decisões do dia-a-dia, fatores críticos de duas naturezas devem ser considerados:

a) Poder importar informações acuradas de uma base de dados, incluindo principalmente: os pedidos dos clientes; os estoques de insumos e de produtos em processo; as estruturas de produtos; os planos de manutenção; os tempos de setup; os ciclos de produção; as quantidades de operadores por operação;

b) Modelar no sistema tanto o processo e as alternativas decisórias do programador como também o já referido conhecimento tácito que faz a empresa funcionar no dia-a-dia, mas que não é encontrado no sistema corporativo. Nesse sentido, além dos exemplos mencionados anteriormente, poderíamos ainda citar outros que evidenciam a especificidade dessa questão no caso em referência, destacando-se a título ilustrativo: os produtos que precisam ser produzidos casados, mas em máquinas diferentes; a melhor seqüência de produção para cores diferentes que usam o mesmo recurso de máquina injetora ou cabine de pintura.

Conclui-se que diante de tantas variáveis no ambiente fabril aliada às tantas exigências do cliente, ao acionar uma produção, diante dos inúmeros caminhos possíveis a seguir, é praticamente impossível fazer essa tarefa sem ter uma ferramenta computacional de apoio à programação da produção no curto prazo, tal qual o simulador. Ou ainda, somente com o conhecimento tácito do planejador e sem uma solução computacional, é utopia pensar que se consegue avaliar rapidamente tantas variáveis e enxergar os impactos operacionais e financeiros (custos e benefícios) de um acionamento de produção.

\section{O Sistema desenvolvido}

Com vista a tratar das questões de gestão da capacidade de produção descritas anteriormente; foi então desenvolvido e implantado - através de uma metodologia de prototipagem - um sistema híbrido de simulação por capacidade finita, que se integrou às soluções de controle e gestão já existentes na empresa.

Esse sistema foi denominado Sistema Integrado de Gestão da Capacidade de Produção (SIGCP).

\subsection{Arquitetura e funcionamento}

O SIGCP é o resultado da integração dos subsistemas: Triton x Baan (ERP) x Sistema Injet x Simulador Trilha x Sistema Injet PNE. A sua arquitetura e funcionamento estão resumidos na Figura 3. 


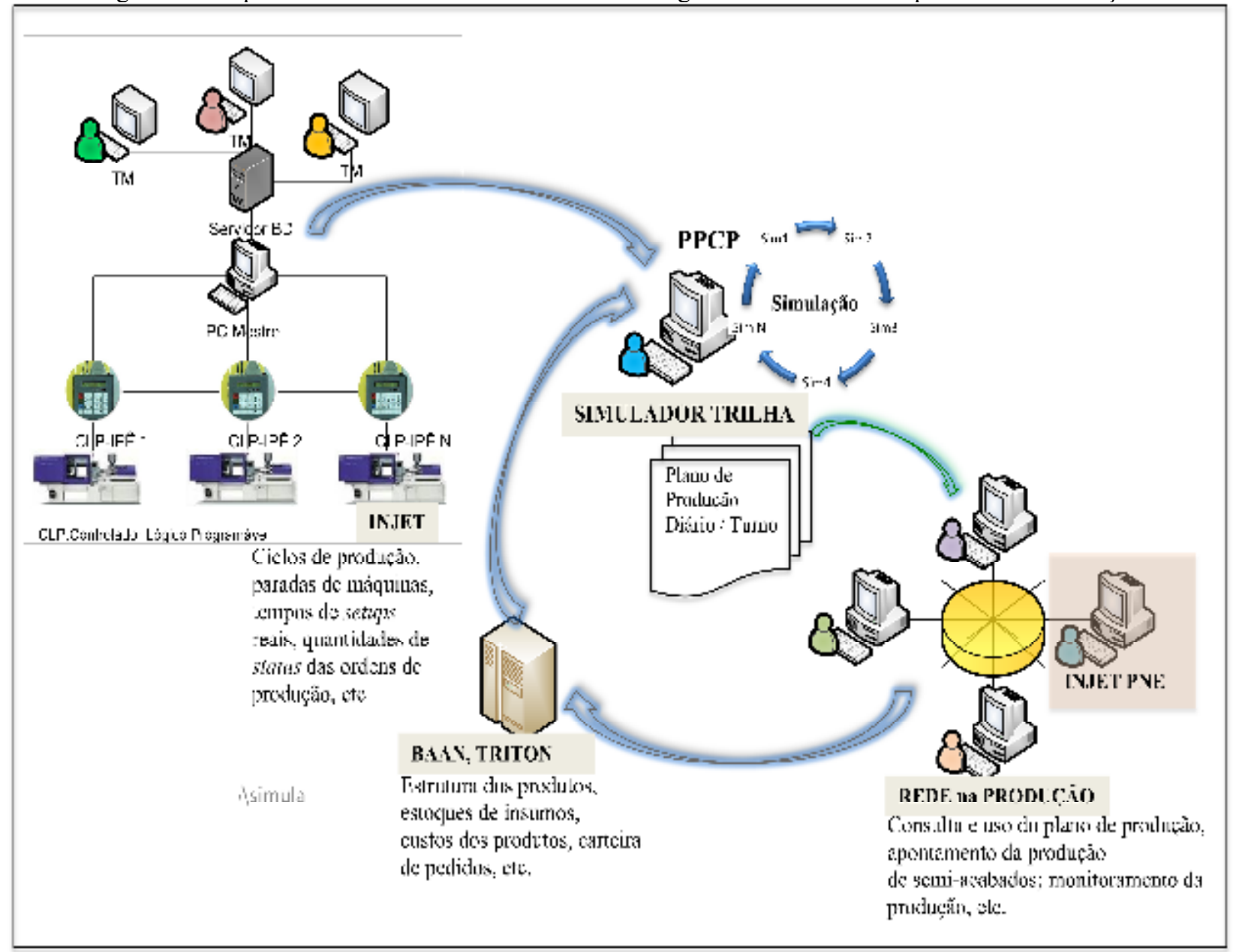

Fonte: Autoria própria (2008)

Em síntese, são feitas as seguintes interfaces entre os sistemas utilizados na empresa, para destes coletar os dados e alimentar o Simulador Trilha:

a) Triton - deste são coletados as informações da carteira de pedidos dos clientes, dentre estas: produtos com saldos de entregas e suas respectivas quantidades, datas de entregas, estoques e valores de faturamento;

b) Baan - neste ERP corporativo, dentre os dados coletados tem-se: estrutura dos produtos; estoques de insumos; dados de trânsito; estoques de produtos semi-acabados; custos dos produtos; dados de compras e das ordens de produções;

c) Injet - "trata-se de uma tecnologia de informação, que auxilia na gestão de melhoria continua do processo produtivo de máquinas cíclicas, operando em células de produção" (CARDOSO, 2009). Deste sistema, coleta-se diretamente das máquinas injetoras dentre outras informações: tempos de ciclos de produção de produto por máquina; planos de manutenções; paradas de máquinas; quantidades de refugos ou scraps; tempos de setups reais; status de andamento das ordens de produções ou apontamentos das produções e estoques de produtos em processo de produção; 
d) Simulador Trilha - este sistema computacional é construído caso a caso, considerando as especificidades de cada sistema de produção, a partir de bibliotecas computacionais (Trilha ToolBox) que por sua vez encapsula algoritmos, rotinas e macros, as quais viabilizam a geração dos simuladores computacionais Trilha. Solução esta que vem sendo desenvolvida e aprimorada desde anos 80 e 90, pela parceria entre a empresa Trilha da Inovação e o Instituto Nacional de Tecnologia (INT-RJ).

Estabelecida as interfaces com os sistemas Triton, Baan, Injet e algumas Planilhas Eletrônicas, o Simulador Trilha opera como receptor e processador das informações da produção em tempo real, avaliando o planejado $\mathrm{x}$ realizado e, dentre as saídas geradas sugerindo os acionamentos de produção;

e) Sistema Injet PNE - este módulo recebe as informações de produção (planejado $\mathrm{x}$ realizado) em tempo real e, os operadores desse filtram as informações relevantes e as retransmitem através de rádios de comunicação para os responsáveis pela produção, para que ações sejam tomadas com rapidez. Este sistema é assim descrito:

\begin{abstract}
O Módulo Injet PNE (Portador de Necessidades Especiais), do Sistema Injet, integra recursos tecnológicos para que deficientes visuais possam se inserir na gestão de melhorias do processo produtivo, com o uso do Sistema Injet. Este módulo possui uma interface que sintetiza em voz eletrônica, através dos alto-falantes do computador, os alertas de perdas, em tempo real, tais como: paradas, refugos e ciclo improdutivo. Além disso, lê os relatórios dos resultados consolidados de produção para o PNE, que por sua vez, se utiliza de um sistema de comunicação interna da empresa para se comunicar com as diversas áreas responsáveis pela produção. Podendo com isso aumentar a rapidez das ações corretivas que eliminam, ou diminuem as perdas acumulativas que estejam ocorrendo (CARDOSO, 2009).
\end{abstract}

Para a implantação do módulo Injet PNE, a empresa contou com o apoio de outras organizações $^{2}$, para viabilizar a utilização do mesmo por pessoas com perda da visão em $100 \%$. Parcerias estas efetivadas com sucesso.

Diante de tantas informações necessárias, um trabalho inicial de pré-implantação do sistema foi realizado, objetivando tornar melhores acuradas as bases de dados da empresa; para posterior disponibilização destas, através das interfaces, para o simulador. Esta é uma etapa fundamental para que o simulador possa sugerir seqüências e acionamentos de produção, que realmente reflitam a realidade da empresa, em todos os seus aspectos.

Assim, o desenvolvimento e implantação do SIGCP se deram através de uma metodologia de prototipagem, que consiste na elaboração de um protótipo que vai sendo aprimorado gradualmente. No caso em questão, esse processo de implantação foi feito através de uma série de visitas nas instalações da fábrica, ao longo de oito meses, envolvendo as seguintes etapas:

2. Associação dos Deficientes Visuais do Amazonas (ADVAM) e o Instituto de Tecnologia José Rocha Sérgio Cardoso (IT JRSC). 
- Conhecimento técnico do processo detalhado do planejamento de produção;

- Definição do protocolo de comunicação de dados dos sistemas corporativos com o simulador;

- Protótipo do simulador;

- Melhorias no simulador;

- Versão completa do simulador;

- Versão final do simulador.

Etapas estas, onde são consideradas todas as informações julgadas pertinentes pela empresa para o processo de planejamento, dentre elas os apontamentos dos dados do processo de produção, de demanda, de estoque e do processo de gestão, de forma a retratar a realidade da empresa.

\subsection{Ferramentas do sistema}

Entre as alternativas disponíveis no simulador para o planejador gerar seqüências de produção para diferentes recursos, inclui-se as diferentes decisões referentes a prioridade; capacidade; fluxo; flexibilidade e cadeia de suprimentos, como pode ser visto nas Figuras 4, 5, 6, 7 e 8 , respectivamente.

As telas que serão apresentadas foram ajustadas de forma a conter nenhum dado tecnológico confidencial da empresa.

Figura 4 - Simulador: Decisão ou regra de acionamento de produção - Prioridade

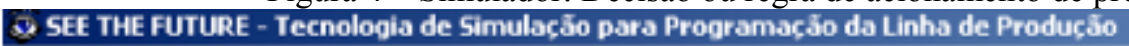

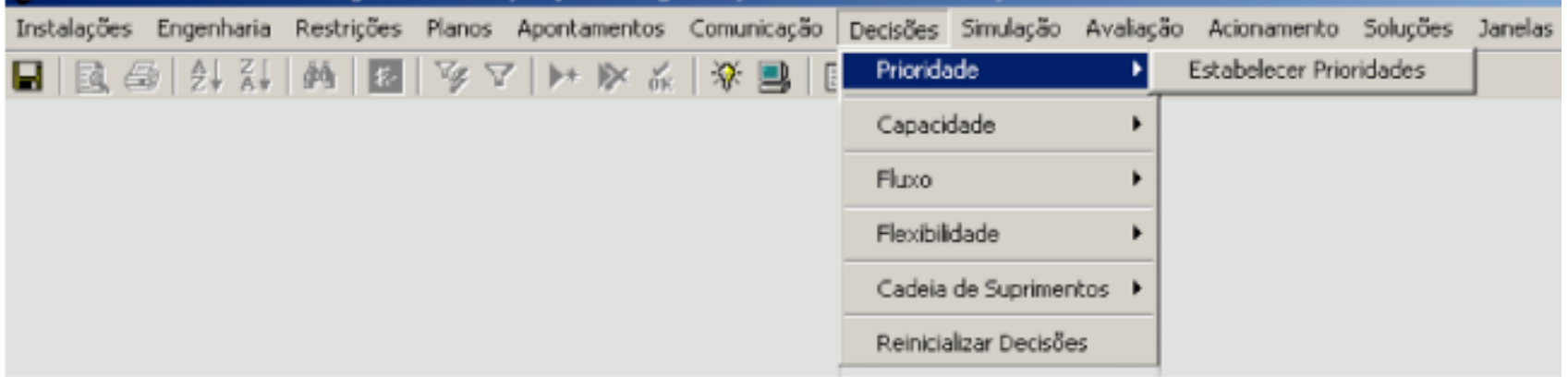

Fonte: Trilha Projetos (2008)

Prioridades podem ser estabelecidas pelo planejador como, por exemplo, o atendimento a um determinado cliente, item, grupo de item ou a um modelo específico. 
Figura 5 - Simulador: Decisão ou regra de acionamento de produção - Capacidade

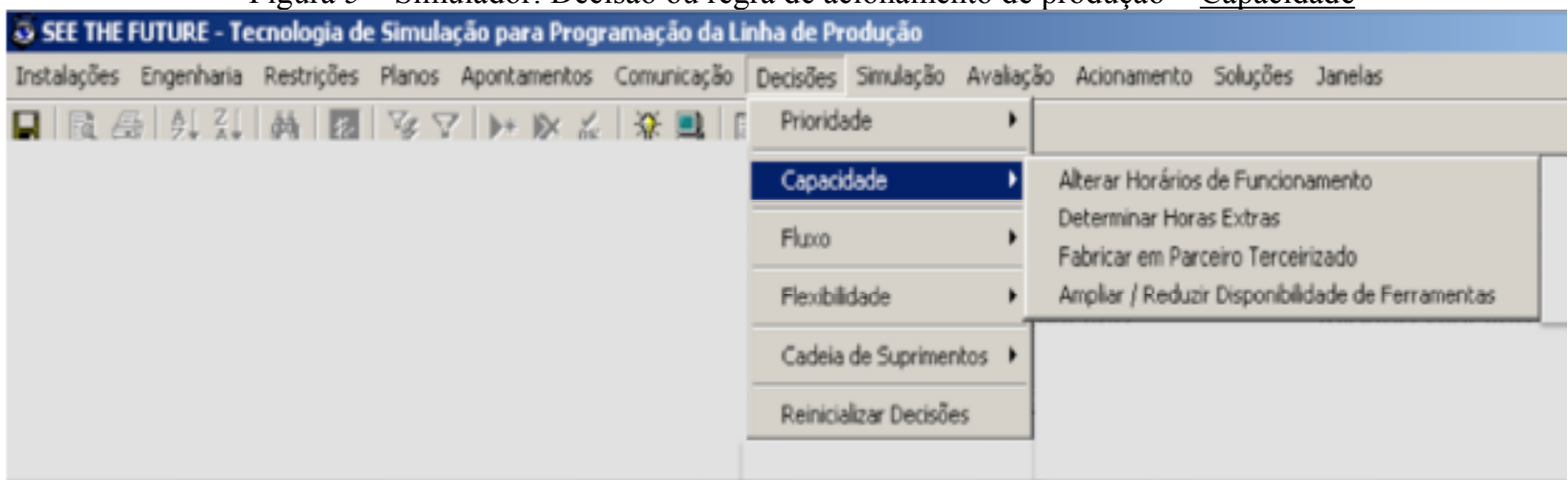

Fonte: Trilha Projetos (2008)

Decisões relativas à capacidade podem ser determinadas pelo planejador como, por exemplo, reduzir ou ampliar a quantidade de dispositivos de produção (exemplo: talha, postiço, controlador de temperatura ou módulo de injeção a gás). Pode-se ainda programar a produção para fornecedores terceirizados, bem como liberá-la, se necessário, em regime de hora-extra, feriado ou domingo.

Figura 6 - Simulador: Decisão ou regra de acionamento de produção - Fluxo

\section{SEE THE FUTURE - Tecnologia de Simulaç̧̃o para Programaçăo da Linha de Produç̋̃o}

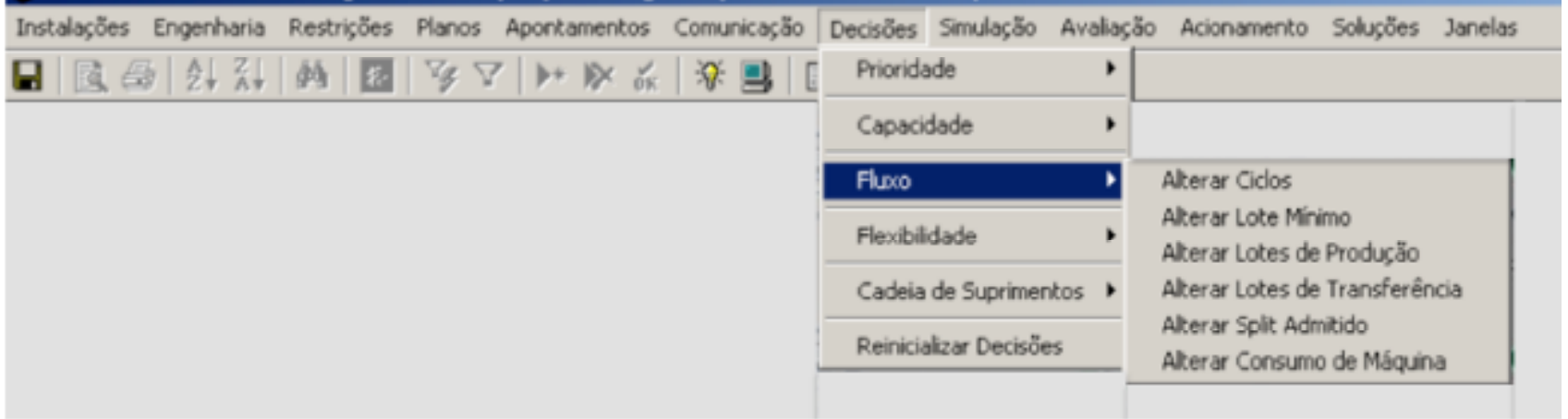

Fonte: Trilha Projetos (2008)

No grupo de decisões de fluxo, considerações como alteração da quantidade de peças de um lote mínimo, lote de produção ou de transferência podem ser feitas. Pode-se também informar se algum molde ficará indisponível para a produção por um período pré-determinado, para que o mesmo não seja considerado no momento da simulação.

Figura 7 - Simulador: Decisão ou regra de acionamento de produção - Flexibilidade

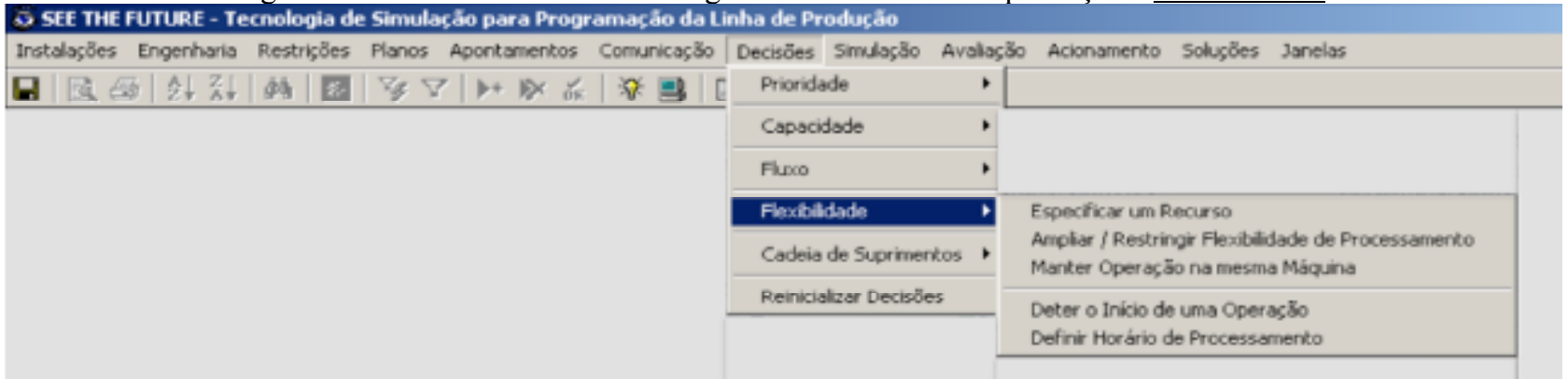

Fonte: Trilha Projetos (2008) 
No agrupamento flexibilidade, é possível que o planejador estabeleça situações do tipo: o uso específico / cativo de uma máquina para a produção de um determinado item; restrição, por determinado período, da produção de um item, mesmo com saldo em aberto na carteira de pedidos. E, por fim, pode-se deixar pré definido um horário para que o simulador faça as interfaces necessárias com os sistemas corporativos e rode automaticamente o plano de produção para posterior análise pelo planejador.

Figura 8 - Simulador: Decisão ou regra de acionamento de produção - Cadeia de Suprimentos

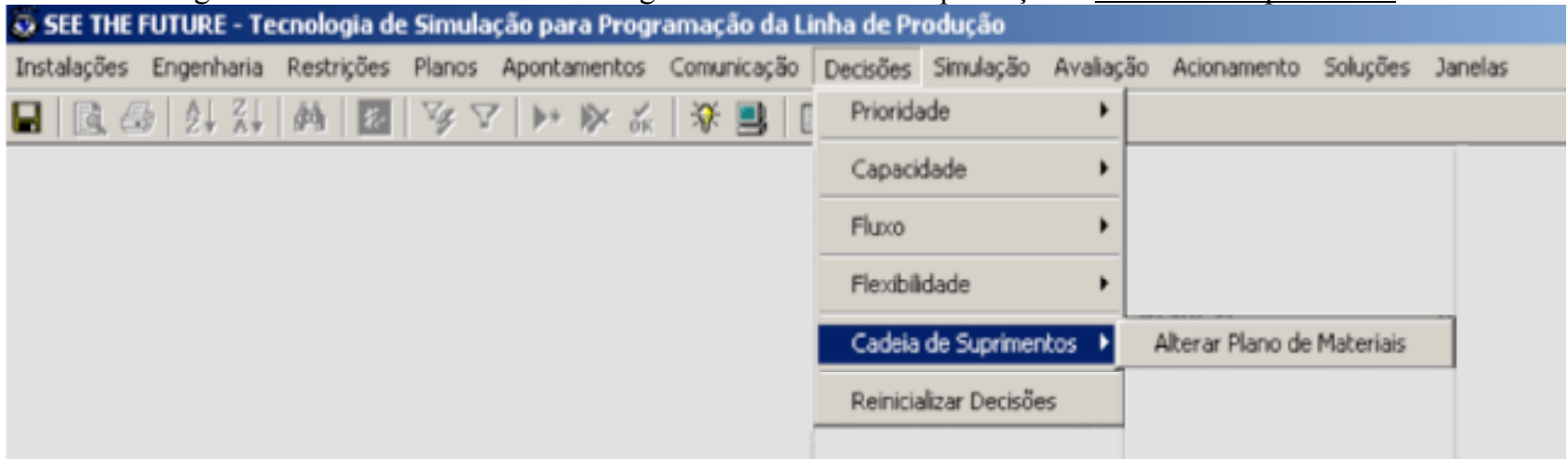

Fonte: Trilha Projetos (2008)

Na regra de acionamento da cadeia de suprimentos, informações relativas ao abastecimento de insumos podem ser informadas diretamente no simulador, independentemente das informações de trânsito que constam no MRP - exemplo: uma renegociação de datas de entrega junto ao fornecedor de um material identificado como crítico, e que ainda não constava na base de dados do MRP.

Após estabelecidas as decisões, o planejador passa para o menu Simulação, conforme Figura 9.

Figura 9 - Simulador: Simulação

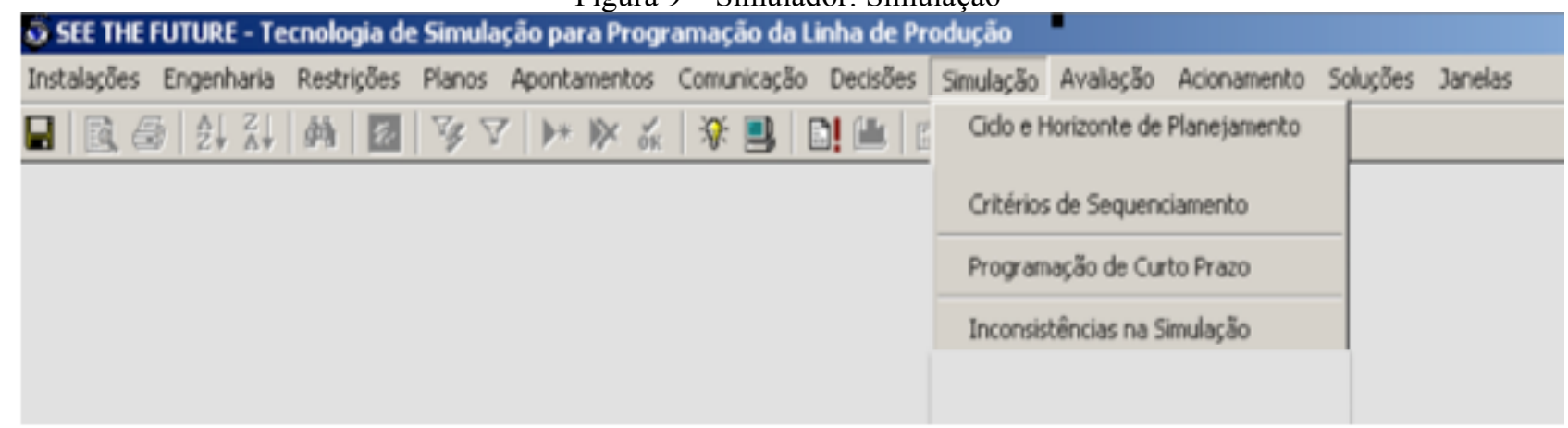

Fonte: Trilha Projetos (2008)

No menu Simulação, o planejador irá informar o período de tempo para a simulação, considerando as variáveis: dia, mês, ano e horário. Informa também quais são os critérios de seqüenciamento que devem ser considerados, como exemplo: menor data de entrega; menor setup; manter cor de produto injetado; ordem de chegada de pedido e manter molde. 
O planejador pode fazer n-simulações e selecionar entre as mesmas aquela que melhor alcança os objetivos estabelecidos, sejam, por exemplo, pontualidade de entrega, fluxo de caixa, utilização de um recurso crítico, entre outras.

\subsection{Saídas geradas pelo sistema}

O sistema, através do simulador, não só disponibilizou para a empresa o plano e controle diário da produção, como a ajudou frente à detecção dos gargalos no fluxo do processo produtivo, contribuindo para a definição de futuros projetos e novos lay-outs da fábrica.

$\mathrm{Na}$ Figura 10 pode ser visto um exemplo das várias avaliações que podem ser feitas com os resultados dos planos gerados pelo simulador. Vale notar que planos considerados pertinentes e efetivos para uma dada circunstância podem ser salvos, para posterior recuperação.

Figura 10 - Simulador: Relatórios para avaliação das sugestões de programação e acionamento da produção 5 SEE THE FUTURE - Tecnologia de Simulaçảo para Programaçảo da Linha de Produçảo

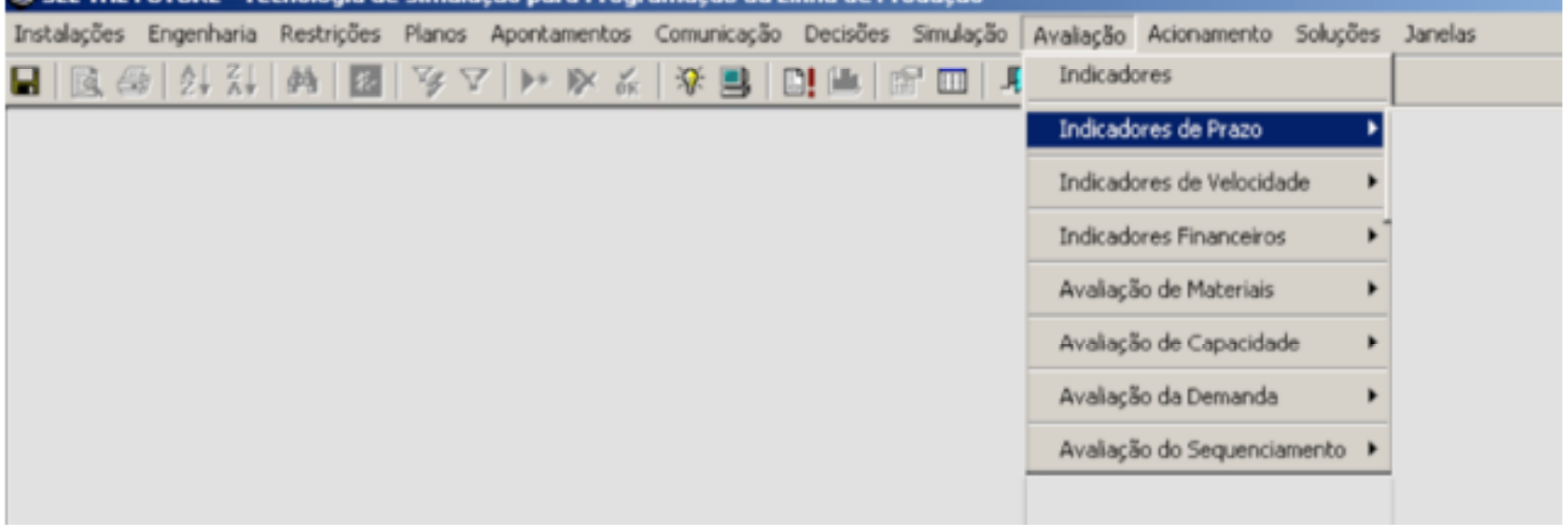

Fonte: Trilha Projetos (2008)

Especificamente, vários aspectos podem ser analisados dentro de cada opção de Indicador / Avaliação, mostrada na figura acima, a saber:

a) Indicador de Prazo: aqui podem ser verificadas as entregas que não poderão ser realizadas e seus respectivos motivos; além disso, são apresentados: (1) o índice de pontualidade de atendimento dos pedidos em carteira para cada cliente e, (2) um relatório com a análise dos motivos de atrasos;

b) Indicador de Velocidade: neste item são indicados o tempo de atravessamento de um produto, desde o momento da sua entrada no processo produtivo até o momento da sua disponibilidade para o faturamento, bem como, a variação de estoques das peças no fluxo da cadeia produtiva;

c) Indicadores Financeiros: neste menu são mostrados indicadores de desempenho do negócio para cada uma das sequências propostas pelo simulador. São exemplos desses indicadores: lucro líquido, lucro econômico, produtividade e retorno sobre investimentos ou ainda, o valor de 
investimentos em estoques;

d) Avaliação de Materiais: este é um relatório para ser usado antes de se seqüenciar e acionar cada máquina, já que o mesmo aponta para materiais que não estão disponíveis para se concluir a produção;

e) Avaliação de Capacidade: aqui se encontram relatórios (gráficos de carga) que apontam para o grau de ocupação das máquinas, bem como das linhas de acabamento, ferramentas e equipes de operadores;

f) Avaliação da Demanda: para cada simulação realizada este relatório aponta para a situação de atendimento da demanda de cada item ou código do cliente, mostrando se o pedido foi concluído, se está em aberto, e o número de peças em estoque (acabadas e inacabadas), ordens em aberto, necessidades líquidas de materiais, entre outros aspectos;

g) Avaliação do Seqüenciamento: nesse item o planejador pode verificar a validade do programa de produção sugerido para cada máquina, para as equipes ou cada ferramenta necessária.

Em suma, com o uso do simulador, o departamento de PPCP pode, a qualquer momento e agilmente, tomar decisões locais (exemplo: seqüenciamento de uma máquina) tendo em vista os objetivos globais e estratégicos do negócio (exemplo: como ser pontual e lucrativo, ao mesmo tempo). Concretamente, o simulador é percebido pela fábrica (colaboradores internos e externos) como um gerador, preciso, ágil e adaptável, de planos de produção para as várias máquinas dos parques de injeção plástica e para as linhas de acabamento. E ainda, como um gerador da lista dos insumos necessários para o cumprimento de um dado plano, apontando para problemas de falta, quando for o caso, como mostram os exemplos das Figuras 11 e 12. 
Figura 11 - Simulador: Plano de Produção - Injeção Plástica

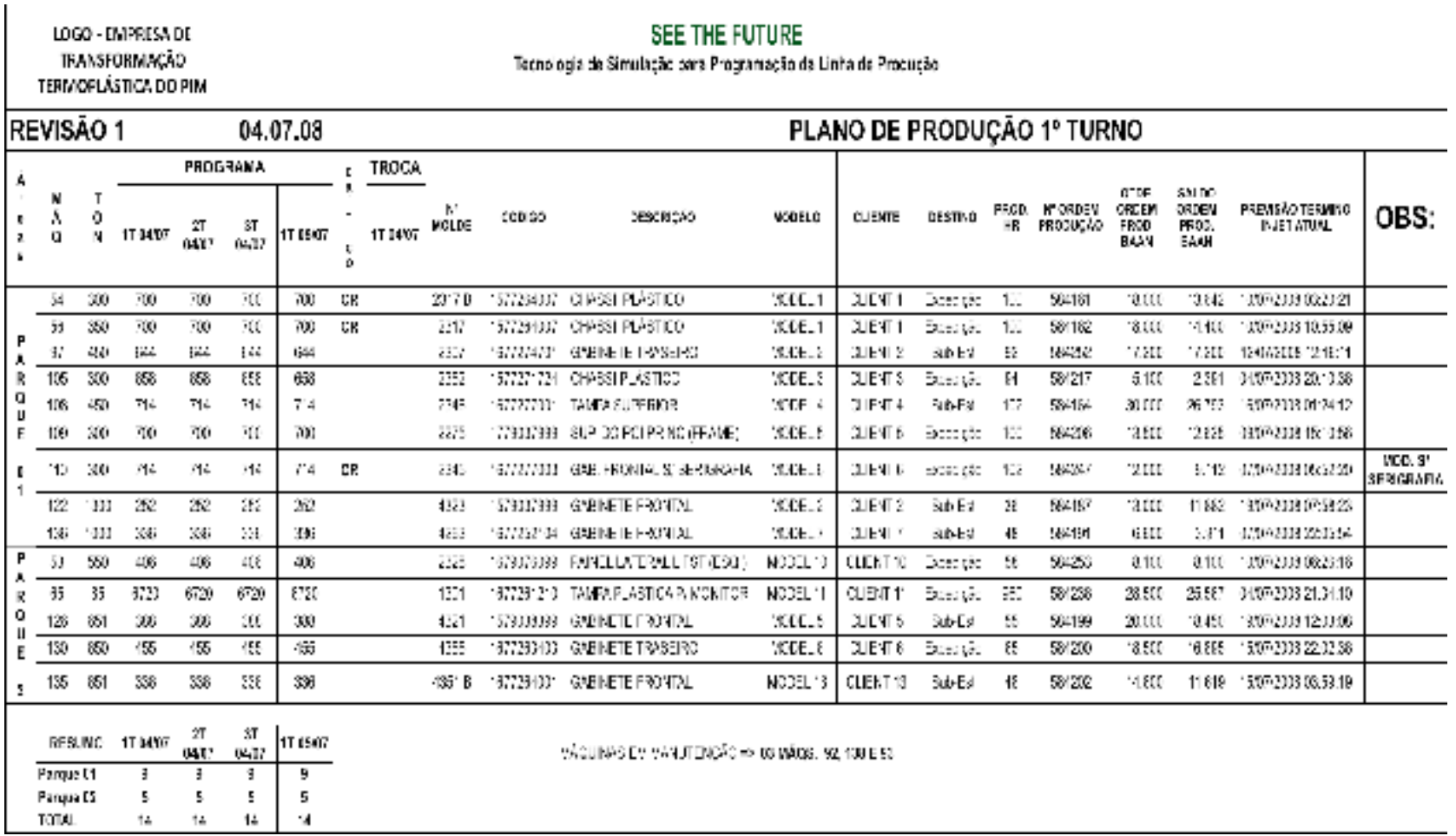

Fonte: Trilha Projetos (2008)

Figura 12 - Simulador: Lista de Materiais para a produção do Plano de Produção - Injeção Plástica

\begin{tabular}{|c|c|c|c|c|c|c|c|}
\hline \multicolumn{4}{|c|}{$\begin{array}{l}\text { LOGO - EMPRESA DE } \\
\text { TRANSFORMACAO } \\
\text { TERMOPLASTICA DO PIM }\end{array}$} & \multicolumn{4}{|c|}{$\begin{array}{l}\text { SEE THE FUTURE } \\
\text { Tecnologia de Simulaçāo para Programaçāo da Produçāo }\end{array}$} \\
\hline & \multicolumn{2}{|c|}{ REVISÁO 1} & \multirow{2}{*}{$\begin{array}{c}04.07 .08 \\
\text { CÓD. } \\
\text { MAT.PRIMA }\end{array}$} & \multicolumn{4}{|c|}{ PLANO DE PRODUÇĀO 10 TURNO } \\
\hline & MẢC & $\begin{array}{l}N^{*} \\
\text { ORDEM } \\
\text { PROD. }\end{array}$ & & DESCRIÇÄ口 & $\begin{array}{l}\text { Eso } \\
\text { Kal }\end{array}$ & $\begin{array}{l}\text { PROD. } \\
\text { HR }\end{array}$ & $\begin{array}{c}\text { NEC HR MP } \\
\text { (KG) }\end{array}$ \\
\hline \multirow{14}{*}{$\begin{array}{l}P \\
A \\
R \\
O \\
U \\
E \\
0 \\
1\end{array}$} & $\overline{5: 4}$ & $=3(1: 3441)$ & 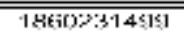 & A.HS-1 I 1(10-MIPM NAIURAI AHS-1 & 11811 & 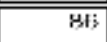 & $101,1481)$ \\
\hline & 5i & 303410 & $1860231599^{-1}$ & B-2 MASTER ME YES ME-A1 ГRETO & 0,0040 & 86 & 0,3410 \\
\hline & 56 & 583523 & $1860 \overline{2}$ & ABS VI HFA-707 KUMHO & 0,2078 & 100 & 20.7800 \\
\hline & 97 & 583711 & 1869 & ABS-VO TRETO & 0.1117 & $160^{-}$ & 17.8720 \\
\hline & 105 & 303433 & 1860231199 & ABS-1TIOO-MГM NATURALABS-1 & 1180 & 86 & 10.1180 \\
\hline & $105^{-1}$ & 303433 & 18602 & UB- 2 MASTCR ME YCS MEAA FRETO & 00040 & 88 & 0,3440 \\
\hline & $100^{-1}$ & 583711 & 186 & TT41M INNOVA & 0.7730 & 63 & 48,6990 \\
\hline & 100 & 583711 & 1869600180 & PIG.GRANFR PIPSIABS MES-1000 & 0.0086 & 63 & 0,5418 \\
\hline & 109 & $583703^{-1}$ & 1860234399 & BSIFC TING PRETO HG MEL-90029 & 0.2072 & 103 & 21,3418 \\
\hline & $110^{-1}$ & 593702 & $18 \mathrm{~B}$ & BS+PCTING & 0.0807 & 103 & 15,2521 \\
\hline & $-122^{-1}$ & 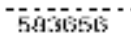 & $\overline{196}$ & & 2.01283 & ถัต & $120,7 \overline{8}$ \\
\hline & 122 & 58 & 186 & Fi & 23 & 130 & \\
\hline & $13 \bar{\beta}^{-1}$ & $59: 3644$ & 1 बिढ & PGAINA & $2,505 \bar{z}$ & 42 & 105,2436 \\
\hline & $13 i i^{-1}$ & 58364 & 186ig) & MAsirn & oinasi & 4 & 1,10144 \\
\hline \multirow{11}{*}{$\begin{array}{l}P \\
A \\
R \\
Q \\
U \\
E\end{array}$} & 4 & $3(1 ; 3450$ & 1460 & 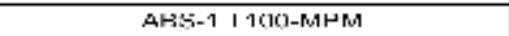 & 111780 & 72 & F) $\{1 \mathrm{H} 40$ \\
\hline & 5 & 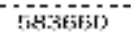 & $18(i)$ & 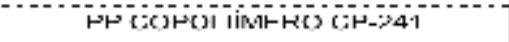 & 0 & (झ) & अभ. 418 \\
\hline & 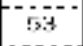 & 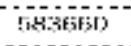 & 18kti & 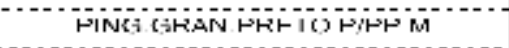 & $\pi 16 \mathrm{i}$ & (झ) & Dititio \\
\hline & $65^{-}$ & 583715 & $800^{-1}$ & RAL & 0,0221 & 313 & 7.0112 \\
\hline & 65 & 583715 & 1860 & FIO CRANULADO CZESE. & 0,0007 & 313 & 0,2191 \\
\hline & 126 & 583639 & 1869 & czrs MBS & 0,0240 & 18 & 1,1520 \\
\hline & 125 & 583639 & 1860 & ГSAI NATURAL 17 & 1,5740 & 18 & 75.5520 \\
\hline & $130^{-}$ & 583877 & 1860233099 & PSAI NATURALABGTEAS & 1.0343 & 80 & 82,0580 \\
\hline & $130^{-1}$ & 583877 & 1869 & PIGEZ CL PIPS 700GC2 & 0.0157 & 60 & 0,9420 \\
\hline & 135 & 583643 & 1860208399 & PSAI NATURAL 478 STYRONLON & 1.5740 & 48 & 75,5520 \\
\hline & 135 & 583643 & 1869612308 & MASTER CZPS MUS1373700GC25148 & 0.0240 & 48 & 1,1520 \\
\hline
\end{tabular}

Fonte: Trilha Projetos (2008) 


\subsection{Aspectos gerenciais e comportamentais}

Para o sucesso da implantação do SIGCP, foi importante quebrar barreiras de resistências a mudanças de todas as partes envolvidas, esclarecendo, envolvendo, comprometendo e treinando pessoas em relação a aspectos dessa nova tecnologia de gestão, ressaltando o seu potencial de resultados.

\section{Avaliação do sistema}

Os resultados obtidos com a implantação do sistema foram divididos sob os aspectos do desempenho do negócio e do processo de planejamento. Onde, após nove meses de implantação do SIGCP, destacam-se os seguintes pontos considerados mais relevantes:

\subsection{Resultado do ponto de vista do desempenho do negócio}

\subsubsection{Melhoria da satisfação do cliente}

Este resultado foi possível, pelo fato do simulador poder propiciar um aumento do horizonte de planejamento de curto prazo, onde conseqüentemente podem ser visualizados com antecedência os problemas futuros de produção e/ou qualquer item crítico. Dessa forma, tem-se em tempo hábil visão para que várias ações gerenciais possam ser tomadas para a solução a tempo; bem como preparar a empresa para as necessidades futuras de demandas produtivas. Essa visão mais abrangente e antecipada das necessidades contribuiu para a empresa aumentar o seu índice de cumprimento dos prazos de entrega dos produtos, produzidos de acordo com as especificações dos clientes.

Com essa nova visão ampliada para a área de PPCP, foi reduzido em 70\% o tempo de resposta de análise crítica dos pedidos feitos pelos clientes, ocasionando um aumento da satisfação dos mesmos.

\subsubsection{Maior rapidez e pontualidade}

Resultado este gerado pela possibilidade de simular e comparar antecipadamente várias alternativas para resolver "gargalos" do fluxo de produção. Onde se ganhou com a:

- Facilidade na análise, referente às sequências de máquinas;

- Minimização de imprevistos, caso eles aconteçam e redução no tempo de reação;

- Consulta de forma integrada dos dados de estoques de insumos, peças em processo de produção, estoque de material semi-acabado e produto acabado; todos reunidos em uma base única, sendo que antes, estes eram dispersos nas diversos sistemas da empresa e em planilhas eletrônicas; 
- Possibilidade de poder simular pedidos extras, ainda não cadastrados em carteira de pedidos; através de um input manual, podendo-se verificar rapidamente possíveis gargalos;

- Visualização prévia da faltas de insumos e impactos de paradas, em quaisquer períodos.

Com a implantação do SIGCP, teve-se um ganho de $83 \%$ de eficiência no planejamento das necessidades de materiais, devido à geração de um relatório de escassez pelo simulador, com até um mês de antecedência, possibilitando a aquisição dos insumos em tempo hábil para a produção, o que também impactou na redução dos custos de produção, ocasionado pela redução na aquisição de insumos por via aérea.

\subsubsection{Otimização de ativos, redução de despesas operacionais, de custos de produção e aumento da lucratividade}

Estes resultados foram obtidos, em função da rapidez com que o simulador pode responder a variações de demanda, de processo e de fornecimento, gerando planos alternativos, verificando entre os mesmos qual o mais adequado para uma dada circunstância, e prontamente alocando atividades aos recursos. Com isso, pode-se reduzir tempos improdutivos de setup, despesas com horas-extras, e sub-contratações.

Em particular, com a utilização do módulo Injet PNE, teve-se uma redução de $0,7 \%$ de paradas de máquinas que, por conseguinte, melhorou em 4,8\% a eficiência do ciclo de produção das mesmas. Conseguiu-se ainda uma redução no índice de refugo de $0,2 \%$, este diretamente ligado às perdas ocasionadas por reinício de máquinas.

Outro importante resultado obtido com o uso do simulador foi a redução de tempos de paradas de máquinas por falta de insumos, possibilitando nesse aspecto um ganho de $70 \%$ de eficiência de realização, já que materiais passaram as estar disponíveis sempre que necessário (a organização e preparação dos mesmos passaram a ser feitas com mais antecedência).

\subsubsection{Redução de estoques}

A possibilidade de se poder reprogramar a produção a qualquer tempo propiciou a redução de incerteza no processo decisório. Isto, por sua vez, reduziu a necessidade de proteção de produção através de estoques de segurança, durante todo o fluxo do processo produtivo. Além disso, as ordens de produção passaram a ser mais precisas, evitando a falta ou a produção em excesso para atendimento ao cliente. Nesse sentido, alguns resultados se destacam, a saber:

- Redução de 75\% na quantidade de peças produzidas indevidamente por erro de planejamento. Antes do simulador, quantidades eram produzidas a mais ou a menos do real necessário, em função da grande variedade de produtos a serem fabricados e da carteira de pedidos desatualizada. Com o simulador essa quantidade passou a ser atendida precisamente tanto em 
termos de quantidade quanto na data do atendimento. O não alcance dos $100 \%$ é em função da não acuracidade da quantidade de peças em estoque, informada pelos setores que ainda no modo manual (digitado) e da carteira não atualizada em 100\% pela área comercial (o que, na grande maioria das vezes, é ocasionada pela falta de informação do próprio cliente);

- Disponibilização de uma área com cerca de $1.000 \mathrm{~m}^{2}$ no almoxarifado de peças semiacabadas, obtida pelo melhor planejamento de produção fazendo uso do simulador, onde se reduziu o nível de estoque de segurança das peças em processo, semi-acabadas e produto final, obtido com a redução da quantidade de peças produzidas por excesso e por falha no planejamento;

- Ganho de cerca de $600 \mathrm{~m}^{2}$ no espaço físico no almoxarifado de insumos, devido a um melhor planejamento na aquisição dos mesmos, já que se passou a comprar somente o necessário, com redução dos lotes de segurança.

Vale ainda ressaltar que o relatório de escassez emitido pelo simulador passou a servir como apoio para que a área de planejamento de materiais pudesse avaliar de forma mais precisa as datas de necessidade de recebimento dos insumos na fábrica, contribuindo assim para se estabelecer níveis mais adequados de estoques.

\subsubsection{Maior flexibilidade}

Com o simulador, pode-se rapidamente responder aos clientes quanto aos prazos de entrega de seus pedidos, sejam esses novos ou alterados. Além disso, pode-se verificar o impacto no desempenho de todo o sistema (em aspectos como pontualidade) quando da necessidade de se introduzir novos produtos no sistema. E sempre que ocorre um imprevisto, como quebra de máquina, falta de material ou pessoas, uma solução alternativa pode ser prontamente gerada para a produção, com os seus resultados para o negócio devidamente avaliados.

\subsubsection{Outros ganhos}

O desenvolvimento e implantação do SIGCP proporcionaram também outros ganhos, alguns inclusive não esperados quando da concepção do projeto.

O uso do simulador permitiu detectar uma série de inconsistências na base de dados do sistema corporativo da empresa, principalmente no que diz respeito a estruturas de produtos.

A implantação do módulo Injet PNE permitiu contribuir com a inserção de pessoas portadoras de deficiência visual em 100\% no mercado de trabalho. Os admitidos nesse projeto com faixa etária entre 35 a 55 anos, foram contratados para trabalhar nos diferentes turnos de produção da empresa, de forma a cobrir as 24 horas das atividades de produção. Com os resultados reais obtidos, outras empresas locais de diversos segmentos foram convidadas para conhecer o projeto específico deste módulo, de forma que também pudessem fazer trabalho análogo e admitir em seu 
quadro pessoas com perfil similar.

Com o uso integrado dos módulos do SIGCP, constatou-se uma comunicação rápida e segura entre as várias áreas da empresa.

\subsection{Resultados do ponto de vista do processo de planejamento}

\subsubsection{Formalização e padronização dos métodos e procedimentos de programação}

Com a implantação do SIGCP, procedimentos formalizados foram criados para que qualquer novo colaborador no departamento de PPCP tenha condições de, valendo-se do simulador, programar a produção obedecendo às regras de acionamento básicas da empresa para tal. Antes da implantação do sistema, o processo de planejamento e programação da produção era 100\% manual e dependia totalmente do conhecimento tácito de cada planejador. Isso gerava transtornos de diversas ordens quando da ausência não-planejada com antecedência de algum planejador.

\subsubsection{Liberação de tempo dos planejadores, chefes e supervisores da fábrica para a melhoria do processo}

Antes da implantação do SIGCP, o tempo para disponibilizar um plano de produção para o chão-de-fábrica era em média de 3 horas. Com o uso do simulador, esse tempo foi reduzido para cerca de 27 minutos, sendo que agora todas as variáveis que afetam a programação podem ser avaliadas.

Com essa redução em cerca de $85 \%$ no tempo de planejamento da produção, o responsável pelo planejamento passou efetivamente a ter condições de fazer análises críticas mais apuradas entre os pedidos dos clientes e os recursos disponíveis na empresa, buscando a melhor programação diária para ambas as partes.

\section{Propostas de projetos futuros de melhoria do sistema}

O uso continuado do sistema integrado de gestão da capacidade de produção permitiu identificar uma série de projetos de melhorias que tornariam o planejamento, programação e controle da produção mais eficaz e eficiente. Dentre estes projetos destacam-se:

- O uso de códigos de barras, com tecnologia sem fio para emitir as ordens de produção - o que contribuirá com um melhor rastreamento do produto e um histórico de produção completo em tempo real;

- O uso de etiqueta inteligente, operado com rádio freqüência e leitura óptica para fazer o apontamento de produção - o que eliminará o apontamento manual e permitirá uma maior acuracidade dos dados e a informação em tempo real dos estoques dos produtos semi-acabados e 
acabados, contribuindo ainda mais para que os acionamentos de produções gerados pelo simulador reflitam fielmente a realidade do chão-de-fábrica.

Em suma, o processo de tomada de decisão se tornará ainda mais preciso junto a todos os envolvidos no negócio.

\section{Conclusão}

Como evidenciam os resultados acima apresentados, a adoção do sistema integrado de gestão da capacidade de produção contribuiu objetivamente para melhorar o desempenho do negócio seja para os clientes, acionistas, colaboradores internos (funcionários) e colaboradores externos (fornecedores).

Com a utilização do simulador passou a ser possível analisar e disponibilizar previamente planos de produção que permitem colocar o produto solicitado em produção: no momento certo, na quantidade certa, dentro das especificações de qualidade certa e no lugar certo.

Além disso, ganhou-se flexibilidade para se poder fazer alterações nas condições de planejamento e produção decorrentes das circunstâncias de mercado, clientes, fornecedores, máquinas e de processos, que constantemente sofrem alterações desejáveis e não desejáveis na vida real. Isto pôde ser alcançado mantendo-se a integridade e a precisão dos dados da organização, bem como gerando procedimentos padronizados de planejamento e execução de produção.

Em suma, com essa nova condição, é possível fazer frente às necessidades de clientes e colaboradores que, com o tempo, evoluem, permitindo assim antecipar e resolver futuros problemas e gargalos de produção.

Outra questão conceitual e gerencialmente alcançada com a implantação do SIGCP foi poder reduzir a lacuna que existe entre as decisões estratégicas assumidas nos níveis mais altos da empresa e as decisões tomadas no dia-a-dia do chão-de-fábrica. Decisões estas que agora podem ter os seus impactos no desempenho do negócio contínuos e dinamicamente avaliados.

Por fim, com a implantação do módulo Injet PNE pode-se contribuir com a inserção no mercado de trabalho de pessoas com 100\% de deficiência visual. Estas passaram a fazer parte de um quadro de competência da empresa, contribuindo para que a mesma se torne cada vez mais competitiva.

\section{Abstract}

In an industrial segment with large investments in assets - such as machinery and molds, whose processing capabilities are limited and where sales plans vary continuously in an attempt to fit the different needs of different customers, programming and daily production control become naturally complex, and has a key role in business performance. This is the case of a thermoplastic company in the Manaus Industrial Pole (PIM) which operates within this framework of variety and variability of demand, products, materials and processes. To cope with this situation, this company has developed and implemented an integrated computer management system of production capacity. Among its modules, this system has a finite capacity scheduling simulator, which considers the particular characteristics of production
} 
processes and management. This will be described in this article. The results obtained using the system include: a $75 \%$ reduction in the quantity of parts produced improperly due to planning errors; $70 \%$ reduction in response time analysis of customer orders; reduction of 2:33 hrs in time for planning a production program, which was previously 3:00 hrs. Some unexpected results were achieved, such as the gain of $1.000 \mathrm{~m}^{2}$ area in the warehouse of parts. With this work it was possible for people with $100 \%$ visual disabilities to do monitoring of production, where they managed with the use of this module, among others, the decrease of $0.7 \%$ machines' downtime.

Key-words: production planning programming and control; computer simulation; finite capacity scheduling.

\section{Referências}

ADVAM (Associação dos Deficientes Visuais do Amazonas). Disponível em $<$ http://www.advam.org.br/index.htm> e $<$ http://intervox.nce.ufrj.br/ advam/>. Acesso em: 03 maio 2009.

CARDOSO, M. A. P.; MAP, C. Sistema INJET: uma tecnologia de apoio à gestão de melhoria contínua do processo de fabricação. Disponível em <http://www.mapcardoso.com.br >. Acesso em: 03 maio 2009.

CORRÊA, H. L.; GIANESI, I. G. N.; CAON, M. Planejamento, programação e controle da produção - MRP II/ERP: conceitos, uso e implantação. 4. ed. São Paulo: Atlas, 2001.

. Planejamento, programação e controle da produção - MRP II/ERP: conceitos, uso e implantação: base $\overline{\text { para SAP }}$, oracle aplications e outros softwares integrados de gestão. 5. ed. - 2. reimpr. - São Paulo: Atlas, 2008.

ITJRSC (Instituto de Tecnologia José Rocha Sérgio Cardoso). Disponível em <http://www.institutojc.org.br/index.php>. Acesso em: 03 maio 2009.

JARDIM, E. G. M.; COSTA, R. S. Técnicas de planejamento e controle da produção. Programa de Pós-Graduação em Engenharia de Produção - Universidade Federal do Amazonas - UFAM. Manaus, 1994.

. Gestão estratégica de curto prazo. Nota Técnica Trilha Projetos Ltda., Rio de Janeiro, 2003.

MESA (Manufacturing Enterprise Solutions Association). MESA Model \& Strategic Iniciatives. Disponível em $<$ http://www.mesa.org/en/index.asp>. Acesso em: 21 junho 2010.

PEDROSO, M. C.; CORRÊA, H. L. Sistemas de programação da produção com capacidade finita: uma decisão estratégica? Revista de Administração de Empresas da Fundação Getúlio Vargas, v. 36, n. 4, São Paulo, 1997.

TRILHA Projetos Ltda. Documentos de sistema, Rio de Janeiro, 2008.

\section{Dados dos autores:}

Nome completo: Maria Rosália da Silva Mizoguchi

Filiação institucional: Universidade Federal do Amazonas - UFAM

Departamento: FT - Faculdade de Tecnologia

Função ou cargo ocupado: Mestranda em Engenharia de Produção

Endereço completo para correspondência (bairro, cidade, estado, país e CEP): Rua Barão do Rio

Branco, 1095, Bairro Flores - Parque das Laranjeiras, Manaus-Amazonas - Brasil, CEP 69058-581

Telefone para contato: (92) 3634-5298

e-mail:rmizoguchi@me.com 
Nome completo: Eduardo Galvão Moura Jardim

Filiação institucional: Universidade Federal do Rio de Janeiro - UFRJ

Departamento: Escola Politécnica - Departamento de Engenharia Industrial

Função ou cargo ocupado: Professor Adjunto

Endereço completo para correspondência (bairro, cidade, estado, país e CEP): Fundação COPPETEC - Centro Tecnológico, Bloco H, Sala 203 - Ilha do Fundão, Rio de Janeiro - Rio de Janeiro - Brasil, CEP 21949-900

Telefone para contato: (21) 2221-0018

e-mail: eduardo@tgps.com.br

Nome completo: Ricardo Sarmento Costa

Filiação institucional: Trilha da Inovação - Projetos Tecnológicos e Educacionais Ltda

Departamento: Diretoria

Função ou cargo ocupado: Engenheiro de Produção, D. SC. - Sócio Diretor

Endereço completo para correspondência (bairro, cidade, estado, país e CEP): Rua da Assembléia, 10/2512, Bairro Centro, Rio de Janeiro - Rio de Janeiro - Brasil, CEP 20011-901

Telefone para contato: (21) 2221-0018

e-mail: ricardo@trilhaprojetos.com.br

Recebido para publicação em: 25/08/2010

Aceito para publicação em: 24/11/2010 